\title{
The growth and infectivity of Leishmania major is not altered by in vitro exposure to $2,3,7,8$-tetrachlorodibenzo- $p$-dioxin
}

\author{
Vera Sazhnev and Gregory K. DeKrey ${ }^{*}$ (])
}

\begin{abstract}
Objective: The numbers of Leishmania major parasites in foot lesions of C57BI/6, BALB/C or SCID mice can be significantly reduced by pre-exposure to 2,3,7,8-tetrachlorodibenzo-p-dioxin (TCDD). One potential mechanism to explain this enhanced resistance to infection is that TCDD is directly toxic to $L$. major. This potential mechanism was addressed by exposing L. major promastigotes and amastigotes to TCDD in vitro and examining their subsequent proliferation and infectivity.

Results: We found no significant change in the rate of in vitro L. major proliferation (promastigotes or amastigotes) after TCDD exposure at concentrations up to $100 \mathrm{nM}$. Moreover, in vitro TCDD exposure did not significantly alter the ability of L. major to infect mice, trigger lesion formation, or survive in those lesions.
\end{abstract}

Keywords: Leishmania major, Dioxin, TCDD, Proliferation, Infectivity

\section{Introduction}

Approximately one million new cases of leishmaniasis occur each year worldwide $[1,2]$. Of the various forms, cutaneous leishmaniasis is the most common, and visceral leishmaniasis is the most deadly. All forms of the disease are caused by infection with protozoan parasites of the genus Leishmania. The most widely studied model of experimental cutaneous leishmaniasis is the L. majorinfected mouse. Some mouse strains (e.g., C57Bl/6) show resistance to $L$. major infection by killing the parasites and controlling their numbers. Other mouse strains [e.g., $\mathrm{BALB} / \mathrm{c}$, and severe combined immunodeficient (SCID)] are lethally susceptible to $L$. major due to insufficient parasite killing, uncontrolled parasite proliferation, and wide-spread dissemination from the site of infection. Killing L. major parasites in mice is typically dependent upon Th1 cells supporting NO production by infected macrophages [3-5].
Previous studies in this laboratory have found that the numbers of L. major parasites in foot lesions of $\mathrm{C} 57 \mathrm{Bl} / 6$, $\mathrm{BALB} / \mathrm{c}$ or SCID mice can be significantly reduced by exposure to 2,3,7,8-tetrachlorodibenzo-p-dioxin (TCDD) prior to infection $[6,7]$. TCDD is a coplanar halogenated aromatic hydrocarbon, a prototypical high-affinity agonist of the aryl hydrocarbon receptor (AhR), and the most common AhR ligand used experimentally to investigate the impact of AhR activation on the physiology of animals [8]. No mechanisms have yet been identified to explain the enhanced T cell-independent resistance to $L$. major infection by TCDD in mice. One previously proposed mechanism [6] is that TCDD is directly toxic to $L$. major. We addressed this potential mechanism by exposing $L$. major promastigotes and amastigotes to TCDD in vitro and examining subsequent proliferation and infectivity. We show here that neither proliferation nor infectivity were significantly altered. These results do not support a direct toxic effect of TCDD on L. major. 


\section{Main text}

\section{Materials and methods}

Animals, parasites and TCDD

Female C57BL/6 and BALB/c mice, 6-8 weeks of age, were obtained from breeding colonies at the University of Northern Colorado with breeding stocks originally obtained from Jackson laboratories (Bar Harbor, ME). Animals were maintained on a 12-h light/dark cycle in Optimice ${ }^{\circledR}$ cages containing Tek-Fresh bedding (Envigo, 7099). Animals were provided with food (Envigo, Rodent Diet 2016) and deionized water ad libitum. Euthanasia was performed with an overdose of $\mathrm{CO}_{2}$.

Leishmania major (LV39, RHO/SU/59/P, Neal, or P strain) promastigotes were maintained by biweekly passage through $\mathrm{C} 57 \mathrm{Bl} / 6$ mice followed by re-isolation from foot lesions on a rotator at room temperature in Promastigote Medium consisting of Schneider's Insect medium supplemented with $10 \%(\mathrm{v} / \mathrm{v})$ heat-inactivated FBS, $5 \mu \mathrm{g} /$ $\mathrm{mL}$ hemin, $50 \mu \mathrm{g} / \mathrm{mL}$ gentamycin, $100 \mathrm{U} / \mathrm{mL}$ penicillin, $100 \mu \mathrm{g} / \mathrm{mL}$ streptomycin, $10 \mathrm{mM}$ Hepes, $116 \mu \mathrm{g} / \mathrm{mL}$ arginine, $36 \mu \mathrm{g} / \mathrm{mL}$ asparagine, $110 \mu \mathrm{g} / \mathrm{mL}$ sodium pyruvate, and $292 \mu \mathrm{g} / \mathrm{mL}$ L glutamine. L. major amastigotes were isolated from the feet of $\mathrm{C} 57 \mathrm{Bl} / 6$ mice infected with 20 million stationary phase promastigotes 17-21 days earlier using methods described previously [9, 10]. Amastigotes were maintained in Amastigote Medium at $37^{\circ} \mathrm{C}$ with humidified air and $5 \% \mathrm{CO}_{2}$ as described by Wenzel et al. [11].

TCDD was purchased from Cambridge Isotope Laboratories (Andover, MA) and dissolved in dimethyl sulphoxide (DMSO). The concentration of TCDD was confirmed by gas chromatography using the method of Laberton et al. [12].

\section{Experimental culture conditions and animal infection}

Parasite cultures were initiated in 24-well culture plates with $5 \times 10^{5}$ procyclic promastigotes or $1 \times 10^{5}$ amastigotes per $1.0 \mathrm{~mL}$ of medium and maintained for 4 days. Amastigote culture conditions were sufficient to maintain purely amastigote cultures for 2 days after which promastigotes became evident. Control cultures included medium only or DMSO at $0.2 \%$ in medium. Treated cultures contained TCDD at concentrations up to $100 \mathrm{nM}$. This maximum concentration was chosen because it approximates the exposure level that has been shown to reduce $L$. major numbers in wild type mice [6]. Amphotericin B $(0.1 \mathrm{mg} / \mathrm{mL})$ served as a positive control for parasite killing. Each culture condition was replicated in triplicate.

To generate stationary-phase promastigotes for infecting mice, procyclic promastigotes were cultured with DMSO or TCDD as described above until stationary phase was achieved. BALB/c mice were then injected with $50 \mu \mathrm{L}$ of PBS containing one million parasites into one rear foot pad as described previously [7].

\section{Data collection and statistics}

Parasite cultures were sampled daily. Viable parasites were enumerated by microscopy using trypan blue and a hemacytometer. Mouse foot lesion thickness over time and lesion parasite numbers on day 28 post infection were determined as described previously [6, 13]. Data were analyzed by analysis of variance using SigmaPlot software (version 13) with treatment and experiment number as sources of variation. Values of $P \leq 0.05$ were considered significantly different.

\section{Results}

\section{Promastigote cultures}

The numbers of $L$. major promastigotes per culture in one representative experiment (out of five) are shown in Fig. 1. Both control and TCDD-exposed L. major promastigotes proliferated rapidly in experimental cultures reaching stationary phase after approximately 3 days and a maximum concentration of approximately 15 million parasites per $\mathrm{mL}$. In contrast, no increase in promastigote numbers was observed in cultures containing amphotericin B. When the results of five independent experiments were combined and areas under the growth curve (AUC) were calculated for each replicate, no statistically significant differences were found

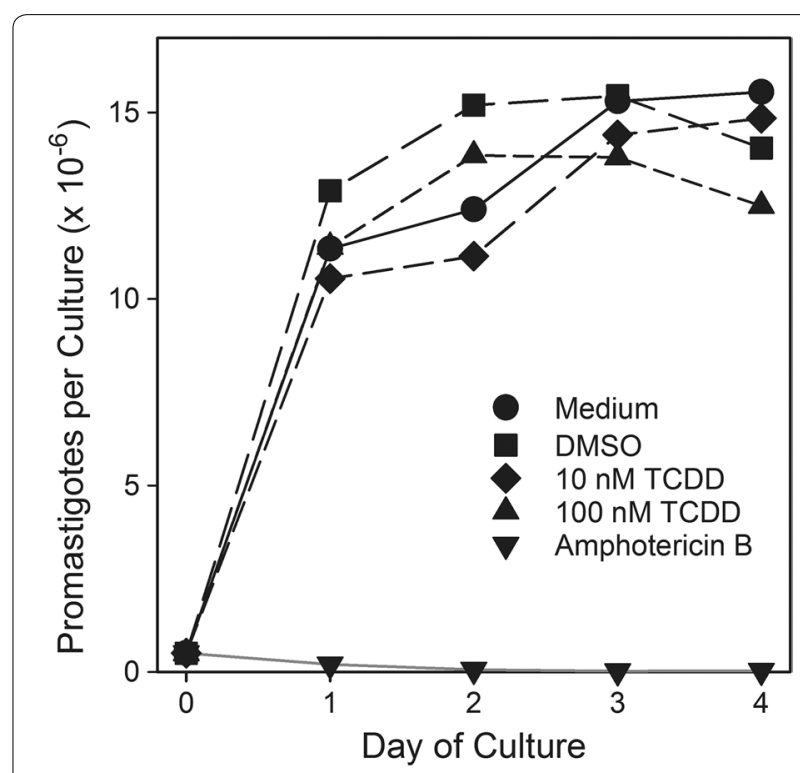

Fig. 1 Promastigote in vitro growth curves. Each line represents the average for triplicate cultures under each condition. The data are representative of five independent experiments 
Table 1 AUC for promastigote 4-day growth curves

\begin{tabular}{lll}
\hline Treatment & Mean* $^{*}$ & SEM \\
\hline Medium only & $1^{\mathrm{a}}$ & 0.62 \\
DMSO & $1.09^{\mathrm{a}}$ & 0.68 \\
$10 \mathrm{nM}$ TCDD & $0.98^{\mathrm{a}}$ & 0.62 \\
$100 \mathrm{nM}$ TCDD & $0.98^{\mathrm{a}}$ & 0.63 \\
Amphotericin B & $-0.09^{\mathrm{b}}$ & 0.01
\end{tabular}

* Mean AUC shown as normalized to medium only control. Means with different letters are significantly different

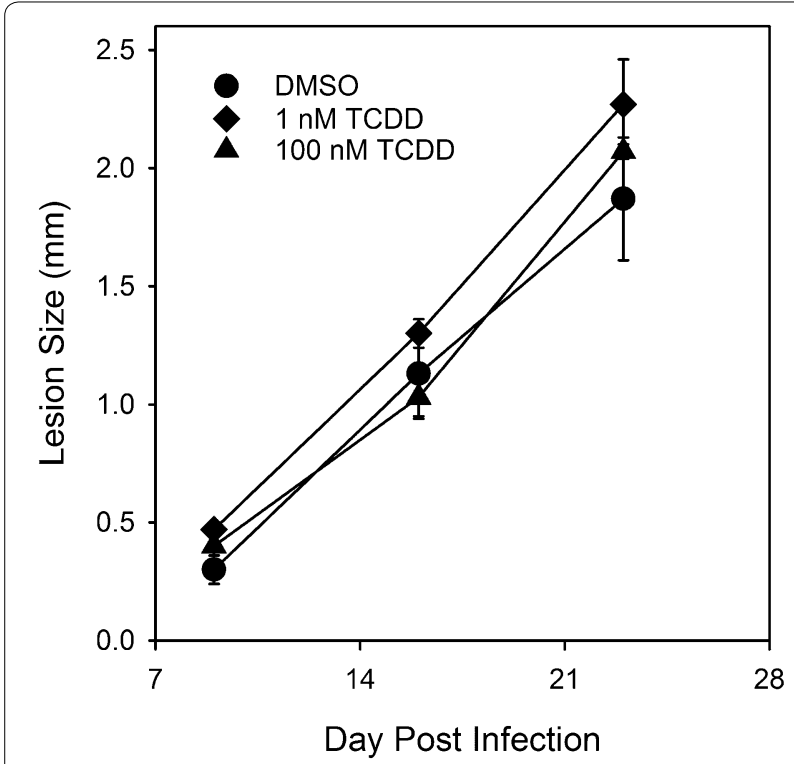

Fig. 2 Lesion size in BALB/C mice after infection with treated parasites. Each line represents the average for three mice. The data are representative of two independent experiments between any treatment groups except in comparison to the amphotericin B treatment (Table 1).

\section{Amastigote cultures}

After 2 days of culture, the number of amastigotes in medium-only cultures was 0.63 million \pm 0.48 million (mean \pm standard error of the mean [SEM]). The number of parasites in the DMSO $(0.64 \pm 0.29$ million $)$ or $100 \mathrm{nM}$ TCDD $(0.31 \pm 0.18$ million $)$ exposed cultures were not significantly different from that found in medium-only cultures or cultures exposed to lower concentrations of TCDD. In contrast, treatment with amphotericin B reduced amastigote numbers by $>95 \%$ to $0.027 \pm 0.012$ million.

\section{Mouse foot lesion thickness and parasite numbers}

Lesion thickness data from one representative experiment (out of two) are shown in Fig. 2. No significant differences were observed between treatment groups at any time point. The numbers of parasites per foot in control BALB/c mice infected with DMSO-exposed L. major 28 days earlier was $15.6 \pm 6.4$ million per foot (mean $\pm \mathrm{SEM}$ ). The numbers of parasites in the lesions of $\mathrm{BALB} / \mathrm{c}$ mice infected with $L$. major exposed to $100 \mathrm{nM}$ TCDD was $18.7 \pm 3.6$ million per foot and was not significantly different from that found in control mice or mice infected with parasites exposed to $1 \mathrm{nM}$ TCDD (16.1 \pm 2.1 million).

\section{Discussion}

TCDD exposure is known to cause many changes in cellular function among common vertebrates with most, if not all, of those effects being mediated through TCDD's action as an agonist of the AhR $[8,14]$. Although AhR proteins have been identified in numerous organisms within the kingdom Animalia (but not outside it), the ability to bind planar aromatic hydrocarbons with high affinity appears to be unique to vertebrates [15]. Leishmania organisms are eukaryotes, but as trypanosomes they are classified outside the kingdom Animalia, and an AhR has not been reported to exist within them. In this study we demonstrated that TCDD exposure did not significantly impact the rate of $L$. major proliferation in culture as promastigotes or amastigotes. Moreover, TCDD exposure did not alter the ability of $L$. major to infect mice, trigger lesion formation of equivalent size, or survive over 4 weeks to equivalent numbers in those lesions. These results suggest that the reduced numbers of $L$. major that we have observed previously in resistant and susceptible TCDD-treated mice $[6,7]$ are not caused by direct TCDD toxicity to the parasite.

\section{Limitations}

This study had some limitations. The culture conditions used to maintain L. major in vitro were not adequate to prevent amastigote transformation into promastigotes beyond 2 days. Therefore, conclusions as to the sensitivity of L. major amastigotes to TCDD are constrained to this time-frame. To our knowledge, no culture conditions have yet been developed to support $L$. major amastigote viability in vitro for extended periods. Because exposures of L. major to TCDD were performed in vitro, this study did not model the influence that TCDD may have on Leishmania in vivo. 


\section{Abbreviations}

AUC: area under the curve; AhR: aryl hydrocarbon receptor; DMSO dimethyl sulphoxide; SEM: standard error of the mean; TCDD:

2,3,7,8-tetrachlorodibenzo- $p$-dioxin.

\section{Authors' contributions}

GD, VS: substantial contributions to study conception and design; data acquisition, analysis and interpretation; manuscript drafting and revision. Both authors read and approved the final manuscript.

\section{Acknowledgements}

We acknowledge R. Titus (deceased) for his inspiration and support of this work.

\section{Competing interests}

The authors declare that they have no competing interests.

\section{Availability of data and materials}

The datasets used and/or analyzed during the current study are available from the corresponding author on request.

\section{Consent for publication}

Not applicable.

\section{Ethics approval and consent to participate}

All procedures using animals were carried out at the University of Northern Colorado in strict accordance with the recommendations in the Guide for the Care and Use of Laboratory Animals of the National Institutes of Health, USA, and with the approval of the University's Animal Care and Use Committee.

\section{Funding}

Funds for this study were provided by the University of Northern Colorado.

\section{Publisher's Note}

Springer Nature remains neutral with regard to jurisdictional claims in published maps and institutional affiliations.

Received: 26 July 2018 Accepted: 31 August 2018

Published online: 04 September 2018

\section{References}

1. WHO. Leishmaniasis in high-burden countries: an epidemiological update based on data reported in 2014. Wkly Epidemiol Rec 2016;91:287-96.
2. Alvar J, Velez ID, Bern C, Herrero M, Desjeux P, Cano J, Jannin J, den Boer M. Leishmaniasis worldwide and global estimates of its incidence. PLoS ONE. 2012;7:e35671.

3. Okwor I, Mou Z, Liu D, Uzonna J. Protective immunity and vaccination against cutaneous leishmaniasis. Front Immunol. 2012;3:128.

4. Handman E, Bullen DV. Interaction of Leishmania with the host macrophage. Trends Parasitol. 2002;18:332-4.

5. Solbach W, Laskay T. The host response to Leishmania infection. Adv Immunol. 2000;74:275-317.

6. Bowers OJ, Sommersted KB, Sowell RT, Boling GE, Hanneman WH, Titus RG, DeKrey GK. 2,3,7,8-Tetrachlorodibenzo-p-dioxin (TCDD) reduces Leishmania major burdens in C57BL/6 mice. Am J Trop Med Hyg. 2006;75:749-52.

7. DeKrey GK, Teagarden RE, Lenberg JL, Titus RG. 2,3,7,8-Tetrachlorodibenzo-p-dioxin slows the progression of experimental cutaneous Leishmaniasis in susceptible BALB/c and SCID mice. PLoS ONE. 2013;8:e76259.

8. Stejskalova L, Dvorak Z, Pavek P. Endogenous and exogenous ligands of aryl hydrocarbon receptor: current state of art. Curr Drug Metab. 2011;12:198-212.

9. Bogdan C, Moll H, Solbach W, Rollinghoff M. Tumor necrosis factoralpha in combination with interferon-gamma, but not with interleukin 4 activates murine macrophages for elimination of Leishmania major amastigotes. Eur J Immunol. 1990;20:1131-5.

10. Green SJ, Crawford RM, Hockmeyer JT, Meltzer MS, Nacy CA. Leishmania major amastigotes initiate the L-arginine-dependent killing mechanism in IFN-gamma-stimulated macrophages by induction of tumor necrosis factor-alpha. J Immunol. 1990;145:4290-7.

11. Wenzel UA, Bank E, Florian C, Forster S, Zimara N, Steinacker J, Klinger $M$, Reiling N, Ritter U, van Zandbergen G. Leishmania major parasite stage-dependent host cell invasion and immune evasion. FASEB J. 2012;26:29-39.

12. Laberton J, Griffin D, Arbogast B, Inman R, Deinzer M. The determination of polychlorodibenzo-p-dioxins in pentachlorophenol and wood treatment solutions. Am Ind Hyg Assoc J. 1979;40:816-22.

13. Lima HC, Bleyenberg JA, Titus RG. A simple method for quantifying Leishmania in tissues of infected animals. Parasitol Today. 1997;13:80-2.

14. Sorg O. AhR signalling and dioxin toxicity. Toxicol Lett. 2014;230:225-33.

15. Hahn ME, Karchner SI, Merson RR. Diversity as opportunity: insights from 600 million years of AHR evolution. Curr Opin Toxicol. 2017;2:58-71.
Ready to submit your research? Choose BMC and benefit from

- fast, convenient online submission

- thorough peer review by experienced researchers in your field

- rapid publication on acceptance

- support for research data, including large and complex data types

- gold Open Access which fosters wider collaboration and increased citations

- maximum visibility for your research: over 100M website views per year

At BMC, research is always in progress.

Learn more biomedcentral.com/submissions 